BMJ Open

Sport \&

Exercise

Medicine

\title{
From barefoot hunter gathering to shod pavement pounding. Where to from here? A narrative review
}

\author{
Peter Francis (D) , ${ }^{1}$ Grant Schofield ${ }^{2}$
}

To cite: Francis P, Schofield G. From barefoot hunter gathering to shod pavement pounding. Where to from here? A narrative review. BMJ Open Sport \& Exercise Medicine 2020;6:e000577. doi:10.1136/ bmjsem-2019-000577

Accepted 30 March 2020
Check for updates

(c) Author(s) (or their employer(s)) 2020. Re-use permitted under CC BY-NC. No commercial re-use. See rights and permissions. Published by BMJ

${ }^{1}$ Department of Science and Health, Institute of Technology Carlow, Carlow, Ireland ${ }^{2}$ Human Potential Centre, School of Sport and Recreation, Auckland University of Technology, Auckland, New Zealand

Correspondence to Dr Peter Francis; peter.francis@itcarlow.ie

\section{ABSTRACT}

Understanding the current prevalence and incidence of running injury from an evolutionary perspective has sparked great debate. Proponents of the evolutionary approach to understanding running injury suggest that humans ran using less injurious biomechanics prior to the invention of cushioned running shoes. Those who disagree with this view, point to the many runners, wearing cushioned running shoes, who do not get injured and suggest that the evolutionary approach is indulging in a 'natural fallacy'. This polarises the scientific debate into discrete categories such as 'shod' vs 'barefoot'. This review aims, first, to describe humans' innate impact moderating mechanisms which arise from our evolutionary legacy. Second, we discuss the impact of footwear on these mechanisms and the potential link to injury in some runners. Finally, we discuss the role of barefoot training in sports medicine and attempt to make some practical suggestions as to how it might be integrated in our modern urban environments.

\section{INTRODUCTION}

Humans have walked and run barefoot for millions of years. ${ }^{1}$ Indirect evidence suggests that footwear emerged as recently as $\sim 30000$ years ago. ${ }^{2}$ The majority of time since then, humans have worn minimalist footwear designed to protect the sole of the foot. ${ }^{3}$ The first indication of fashionable footwear beginning to alter the shape of the foot emerged a little over 100 years ago ${ }^{4}$ and the invention of the mass market cushioned running shoe is as recent as $\sim 1970 .^{5}$ Therefore, large changes in footwear have occurred in a very short space of time relative to human evolutionary history. When rapid changes in physical or nutritional environments occur, it is described as a mismatch between biological evolution (occurring slowly over millions of years) and cultural evolution (occurring rapidly due to events such as the industrial or technological revolution). This mismatch has been proposed as a hypothesis, mainly by evolutionary biologists, to explain some of the current burden of chronic disease. ${ }^{6}$ To

\section{What is already known on the topic?}

- Plantar cutaneous input from the foot can influence whole body postural stability and kinematics during movement.

- Foot morphology differs between those who grow up habitually shod and barefoot.

- Differences in running kinematics exist between shod and barefoot runners.

- Differences in running kinematics exist when running on soft compared with firm surfaces.

\section{What are the new findings?}

This narrative review synthesised information from the fields of evolutionary biology, anatomy, physiology and biomechanics to suggest how runners innately moderate impact.

- We make a number of suggestions on how these innate impact-moderating mechanisms may be influenced by footwear and subsequently increase the risk of running injuries.

- We offer practical suggestions as to how runners may integrate barefoot training in an urban environment.

provide an example, diseases which did not previously exist or were rare such as type 2 diabetes, ${ }^{7}$ osteoporosis ${ }^{8}$ and plantar fasciitis, ${ }^{9}$ are thought to be contributed to by rapid changes in energy availability, physical activity and modern footwear use.

Using an evolutionary lens to understand the current prevalence and incidence of running injuries has sparked great debate among scientists. ${ }^{1011}$ Unlike other primates, the human foot has an arch capable of both stiffness and deformation ${ }^{12}$ to varying degrees dependent on the terrain. It can store and release energy via springs (ligaments, aponeurosis, tendons) in order to make efficient use of muscle work during running. ${ }^{6} 1314$ In fact, it is for this reason that the Achilles tendon is $~ 10$ times longer in humans compared with other primates. ${ }^{6}$ Coordination between the spring system 
and the muscular system during running is thought to be optimised via using a mid to forefoot strike which allows the foot to stretch and recoil as the muscle moves from eccentric to concentric work. ${ }^{13} 15$ On this basis, it is suggested that humans likely ran with a mid to forefoot strike prior to the invention of running shoes. ${ }^{1}$ An estimated $\sim 75 \%$ of runners (recreational, $>5 \mathrm{~km}$ ) now use a rearfoot strike (RFS) ${ }^{16}$ and some researchers suggest that this increases the risk of certain types of stress pathology (ie, plantar fasciitis, medial tibial stress syndrome) in some runners. ${ }^{17-19}$ The loading rate or instantaneous loading impulse on ground contact may be greater during a RFS which does not allow for a gradual deceleration, ${ }^{19}$ as would be the case with a mid to forefoot strike. ${ }^{20}$

Although, that is the essence of the debate, the aetiology of running injury is multifactorial. ${ }^{19}{ }^{21}$ The incidence of running injury is high relative to many team sports ${ }^{22}$ and other aerobic exercises ${ }^{23}$ but there are many runners who do not get injured, including those that use a RFS. In fact, most world championship marathon runners use a RFS. ${ }^{24}$ Even habitually barefoot modern hunter-gatherers who farm more than hunt and therefore, do not require running as part of activities of daily living, predominately use a RFS up to speeds of $\sim 5.0 \mathrm{~m} / \mathrm{s} .{ }^{25} \mathrm{~A}$ tendency to RFS is also seen in habitually barefoot children, ${ }^{26}$ perhaps due to lower body mass; women who do not $\operatorname{run}^{27}$ and in runners running on soft surfaces. ${ }^{28}$ It is clear that body mass, maturation, sex, running experience, speed and surface influence foot strike patterns in addition to footwear. That being said, we speculate that adult runners, regularly required to run at moderate speeds, without shoes and on firm surfaces would likely have used a mid to forefoot strike pattern prior to the invention of shoes. ${ }^{1} 9$ This strike pattern would allow runners to capitalise on innate impact moderating mechanisms (safety) and to maximise running speed for a given energy cost (efficiency). ${ }^{30} 31$

The link between footwear, foot strike patterns and running injury may be better discussed in the context of certain types of runners and or certain types of injuries. For example, given that taller and heavier runners have a higher risk of injury ${ }^{21}$ and women with a history of plantar fasciitis ${ }^{19}$ experience greater loading rates, footwear and foot strike may become more important in certain groups of runners. The aim of this review is to discuss how footwear alters human innate impact moderating mechanisms and how that may contribute to running injury. Towards this aim, the paper is divided into three sections:

1. The innate capacity of humans to moderate impact during dynamic activities.

2. The impact of footwear on innate impact moderating behaviour and injury risk.

3. The use of barefoot training to reduce the incidence of running injury.
THE INNATE CAPACITY OF HUMANS TO MODERATE IMPACT DURING DYNAMIC ACTIVITIES

\section{The spring-like function of the human foot}

Biotensegrity is the term used to describe how human tissue (ie, skin, organs, muscles) repels sudden deformation through tensioning and stiffening elements. ${ }^{32}$ In the context of human movement, biotensegrity may be considered the property of tissue that underpins passive dynamics (tissue stretch and recoil during movement). ${ }^{33}$ Movement of the foot into plantar flexion or dorsiflexion creates skin deformation sufficient to alter both skin thickness and hardness on the plantar and dorsal aspects of the foot. ${ }^{34}$ Alterations in skin hardness and thickness even by nonweight-bearing movement have led Smith and colleagues to suggest that it is possible for skin movement to alter the threshold required to stimulate cutaneous mechanoreceptors. ${ }^{34}$ These receptors play a key role in gait and postural stability. ${ }^{35}$ During running, subcutaneously, the plantar aponeurosis, plantar ligaments and spring ligament maintain integrity of the arch and provide a strain energy storing mechanism that is reduced by removing each structure in turn. ${ }^{143738}$ These structures in conjunction with the Achilles tendon make a significant contribution to the total energy turnover during the stance phase of running. ${ }^{13} 38$ The contribution of these 'springs' is perhaps best illustrated by the fact that the caloric cost of running a $10 \mathrm{~min}$ or $7 \mathrm{~min}$ mile is the same. ${ }^{13}$ The ability of these structures to recoil is optimised by positioning the foot in a mid to forefoot position which allows the Achilles tendon and plantar arch to stretch during the early stance phase. ${ }^{1315}$ The properties of these tissues are thought to be able to alter leg stiffness within $\sim 40-60 \mathrm{~ms}$ (prior to any identifiable trace on Electromyography (EMG)). These responses are likely to overlap with sensory reflexes occurring 50-100 ms after landing, which are followed by EMG responses due to efferent motor activity 70-188 ms after landing. ${ }^{33940}$ Biotensegrity is influenced by strain previously experienced by the tissue, foot position and muscle-tendon architecture ${ }^{32}$ Positioning the foot and leg in a position whereby muscular and connective tissue components have mechanical advantage creates a more favourable limb position for the absorption of collision forces on ground contact. ${ }^{41}$

\section{The sensory function of the foot}

The sole of the foot contains the same class of mechanoreceptors (fast and slowly adapting type I and II) as the palm of the hand. Each of the four types of mechanoreceptors are uniquely sensitive to deformation and motion of the skin. Mechanoreceptors transmit tactile and proprioceptive feedback via sensory nerves to the central nervous system. ${ }^{42}$ Sensory feedback from the skin interacts with descending motor commands at the spinal cord which allows reflexive modulation of motor neuron excitability. ${ }^{43}$ The density of mechanoreceptors on the plantar aspect of the foot appears to follow a proximal-distal and mediolateral gradient, that is, a higher density of mechanoreceptors towards the lateral edge of the foot, the metatarsals and digits. ${ }^{43}$ An increase in the density of mechanoreceptors 
improves tactile sensitivity to small changes in stimulus amplitude and spatial awareness. Control of balance and gait is dependent on the control of the centre of mass over a base of support. An increase in mechanoreceptors towards the lateral edge of the foot and the toes is thought to be important to subtly identify the outer limits of the base of the support. ${ }^{43}$ This would be less important medially, first because the risk of falling or ankle sprain would be lower and second, because a well-developed arch is rarely in contact with the ground when barefoot. The lower density of mechanoreceptors and therefore, higher threshold required to stimulate the heel may be due to the heel's role in absorbing force during ground contact on walking and the fact that it cannot be independently manipulated. ${ }^{43}$ Interestingly, noxious plantar stimulation of the heel or plantar surface near the metatarsal-phalangeal joints result in plantar and digit flexion. ${ }^{4244}$ The result of this in a weightbearing position is the redistribution of load towards the lateral edge of the foot and distal digits as the arch rises. Conversely, stimulation of the medial longitudinal arch, as would be in the case in arch-supported shoes, results in dorsiflexion of the ankle and digits. ${ }^{45}$ Reducing cutaneous feedback to the plantar surface of the foot can alter whole body posture, ${ }^{46}$ muscle activity and limb kinematics during walking. ${ }^{47}$ Even manipulating sensory input to the dorsum of the skin is sufficient to alter joint (ankle and knee) kinematics during walking. ${ }^{48}$ These findings combined suggest that cutaneous input from the foot in conjunction with the vestibular system, ${ }^{49}$ neuromuscular system and vision play an integral role in the precise control of balance and gait. ${ }^{35}$

\section{Muscles in control of movement}

The intrinsic (or local) muscles of the feet, in conjunction with the ligaments and plantar aponeurosis, act as a dynamic arch support in order to provide a platform for global muscles (hip, knee, ankle) to act on during dynamic activities. $^{12}{ }^{50}$ These structures combined are intimately related to reflexive systems associated with stabilisation of the limb. The role of the intrinsic foot muscles may be considered akin to the local muscles of the neck. ${ }^{12} 51$ The intrinsic foot muscles are subject to intrinsic, kinetic, mechanical, proprioceptive and reflex demands associated with postural stability. ${ }^{12}$ A reduction in local or intrinsic muscle strength may allow external forces generated by global muscles to overload structures not designed for load absorption, for example, osteoligamentous structures in the cervical spine ${ }^{52}$ or non-contractile structures of the feet such as the plantar fascia. ${ }^{12}$

During running, muscles are continuously operating via both feedforward (in anticipation via vision) and feedback (in response via sensory physiology) mechanisms. ${ }^{39}$ Passive (biotensegrity) and neural (reflex arc's) dynamics appear to be particularly dominant in the initial ground contact phase. ${ }^{33}$ This may be especially true around the foot and ankle joints which make contact with the ground first and appear to have muscle-tendon architecture (short fibres and long tendons) designed for fast response. ${ }^{39}$ The proximal muscles (long-fibred) may be seen to be more dominant in initiating action (feedforward) and in absorbing energy subsequent to feedback from passive and reflex responses. ${ }^{39}$ Indeed, it was the evolutionary transition to a sideways-facing pelvis and the proximal muscles of the hip (notably the gluteal muscles) that facilitated efficient bipedalism and eventually long distance walking and running. Running is a series of hopping actions from one leg to the other and our gluteal muscles essentially stop us from falling over. ${ }^{6}$ Muscle responses will perhaps be most evident via kinematic changes at the major joints and the extent of preactivation in anticipation of the expected ground contact. In many runners, acutely and at submaximal speeds, barefoot running results in a reduction in stride length and increased plantar and knee flexion. ${ }^{53-55}$ Runners ( $\mathrm{n}=16$; Kenyan runners) who are habitually barefoot demonstrate lower loading rates (force) compared with their shod counterparts. ${ }^{20}$ This is thought to be due to the optimisation of the limb position for ground contact and the preactivation of muscles in anticipation. ${ }^{54-56}$ Previously shod runners who respond to a barefoot running intervention demonstrate greater plantar flexion, increased biceps femoris and gluteus medius preactivation, and decreased rectus femoris muscle activity between testing periods. ${ }^{56}$ We speculate that the integration of the passive and sensory subsystems results in a motor response whereby joint positioning is optimised to provide muscles and tendons with mechanical advantage for the absorption of ground contact (figure 1).

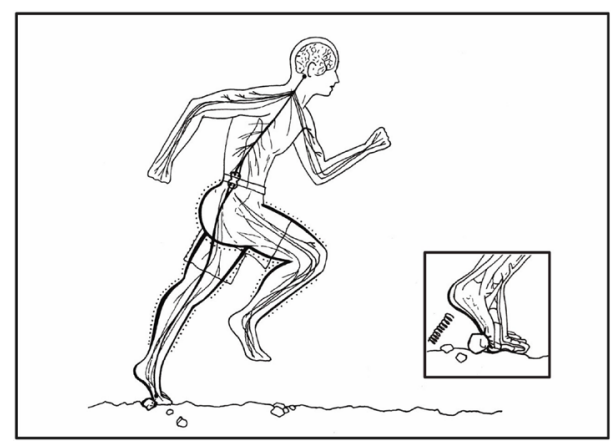

Figure 1 Humans' innate impact-moderating mechanisms on variable terrain. As the foot makes contact with the pebble (inset) it causes deformation of the skin and underlying tissues. This alters the position of the foot and the location and stimulation of the mechanoreceptors. Rapid and subtle adjustments are made via reflex arcs arising from stimulation of sensory nerves and modulation at the spinal cord. Based on this information (feedback) and visual input (feedforward) the brain directs motor output of the major muscles. Landing with a degree of flexion at the hip, knee and ankle provides mechanical advantage for muscles (gluteal, hamstrings, quadriceps, triceps surae) to absorb energy (eccentric control of deceleration) and generate propulsion during extension (concentric phase). Positioning the foot in the forefoot position (inset) on landing allows the Achilles tendon and the medial longitudinal arch (assisted by intrinsic foot muscles) to stretch as the heel comes towards the ground and rebound like a spring. 
THE IMPACT OF FOOTWEAR ON INNATE IMPACT MODERATING BEHAVIOUR AND INJURY RISK

The human foot is composed of 26 bones and 33 joints, and is supported by a complex mesh of ligaments, aponeuroses and intrinsic foot muscles. ${ }^{12}$ Its unique features give rise to a nimble structure capable of traversing the irregular surface it evolved to navigate. We suggest the regular interior of a shoe and the paved consistency of concrete may inhibit the recoil properties associated with the biotensegrity of human tissues. First, in a shoe, skin stretch and deformation may be less in response to subtle changes in the environment and second, a predominance of RFS in shod runners does not allow the plantar arch and Achilles tendon to stretch in the early stance phase. A cushioned shoe offers protection for the skin but reduces tactile sensitivity of the plantar aspect of the foot. Recent data suggest that this reduction in sensitivity during walking contributes to an impact impulse three times greater compared with when walking barefoot or in minimalist shoes. ${ }^{57}$ These authors suggest we are likely adapted to cope with two to three times the loading rate and a third the loading impulse, suggesting that humans in modern footwear do not experience evolutionarily normal loading from walking. During treadmill running, the proportion of RFS increases as the amount of cushioning in shoes increases. ${ }^{58}$ We suggest that this dampening of sensory input will impair subtle refinements in relation to the control of the centre of mass over a moving base of support. It is for this reason, the use of cushioned footwear is likely what contributes to concentrated pressure at specific locations such as the heel and metatarsals, ${ }^{5960}$ thus negating the specialised role of the lateral aspect of the foot and the toes in the fine control of movement. ${ }^{43} 61$ In the context of a runner, a supportive shoe will provide a stimulus to the medial aspect of the foot, that is absent when running barefoot. We speculate, that stimulation of this region of the foot ${ }^{44}$ may be one of the factors (in addition to a cushioned heel) that encourages a RFS in $\sim 75 \%$ of runners.

Biotensegrity and tactile sensitivity are altered acutely by the use of footwear whether individuals are habitually shod or barefoot. Considering that motor output is governed, in part, by input from these systems, it is expected that shoes will alter whole body movement as a result of changes in muscle work. However, the longterm impact of footwear on muscle work is perhaps best observed from data comparing habitually shod and barefoot populations or changes occurring when either population alter their habitual footwear habits. Differences in foot morphology between those who have never worn shoes and those who are habitually shod have been described since $1905 .{ }^{4}$ The main developmental consequences of growing up shod compared with barefoot appear to be a reduction in arch height and a narrower foot. ${ }^{62} 63$ These developmental differences are thought to contribute to higher peak pressure at the heel and metatarsals in shod populations. ${ }^{59}{ }^{60} \mathrm{By}$ contrast, habitually barefoot populations demonstrate wider feet, a lower prevalence of flat feet and more equally distributed peak pressures towards the lateral foot and distal phalanges. ${ }^{45} 596164$ The differences in foot structure, particularly at the arch, are thought to be due to the function of the intrinsic foot muscles. A collapsed arch is associated with atrophy of the intrinsic foot muscles. ${ }^{12}$ A similar reduction in arch height is also observed with fatigue of the intrinsic foot muscles. ${ }^{6566}$ Increasing the amount of time spent barefoot, walking in minimalist shoes or doing foot strengthening exercises increases intrinsic muscle size and can increase arch height. ${ }^{67} 68$

The consequences of wearing cushioned running shoes appear to be linked to the consequences of habitual footwear use such as a propensity towards pronation (reduced arch height) and more concentrated peak pressures (facilitated by RFS). These loading characteristics are associated with higher risk of stress pathology in runners. ${ }^{18} 19$ 69-73 Indeed, the majority of running injuries in shod populations are repetitive strain injuries to non-contractile tissues. ${ }^{23}$ We speculate, as McKeon and colleagues $^{12}$ have, that many of these injuries, particularly below the knee, will be contributed to by loading characteristics and intrinsic foot muscle dysfunction associated with the use of cushioned footwear. In the only prospective study to compare injuries between shod and barefoot runners, shod runners reported more plantar fasciitis (11 vs 3) and knee injuries (12 vs 5) than barefoot runners. Conversely, barefoot runners reported a greater number injuries to the calf-Achilles tendon complex (14 vs 5). ${ }^{74}$ These findings may be expected due to the increased requirement for plantar flexor muscle work during barefoot running. ${ }^{54}$ We speculate that injury to the plantar flexor complex will be especially common in adults who were not habitually barefoot growing up and/or have progressed their barefoot training too quickly. However, muscles and tendons have the capacity to adapt in a way that structures like the plantar fascia cannot. These injuries among barefoot runners may indicate a transference of load towards structures designed for load absorption. That being said, greater knowledge on the optimal method of transition for runners who do wish to run barefoot is required. Otherwise, this form of training could increase rather than lower the incidence of running injury.

Patellofemoral pain syndrome is the most common running injury in adults and is particularly prevalent in women. ${ }^{23}$ The mechanism of injury has commonality with that seen in more traumatic injuries of the knee (ACL), that is combined adduction and internal rotation of the femur. ${ }^{75} 76$ These mechanics are suggested to occur due to an inability to decelerate the hip and knee using eccentric muscle work from the posterior chain. ${ }^{77}$ This leads to athletes adopting more upright postures and relying on the anterior musculature (quadricep dominance) for stability at the knee. ${ }^{78}$ A longer stride 


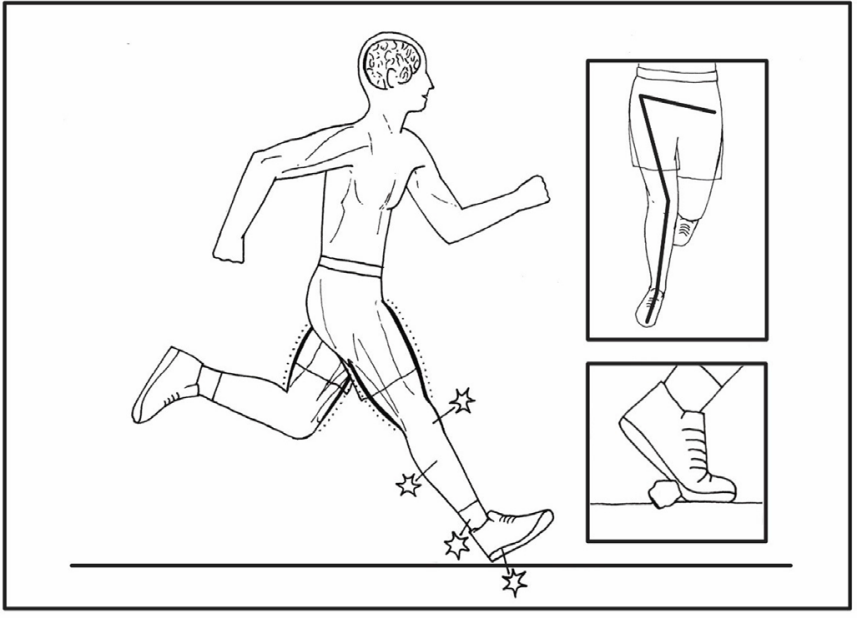

Figure 2 The proposed mechanism by which shoes may facilitate biomechanics which predispose some runners to certain types of injury. Cushioned footwear encourages a rearfoot strike which is associated with an extended lower limb and a more upright torso. This in turn encourages a longer stride length in which the base of support is located further away from the centre of mass. In this position, the limb does not have mechanical advantage during ground contact which may encourage excessive breaking forces and increased repetitive tensile loading due to prolonged eccentric muscle contraction. One of the reasons these more 'blunt' running mechanics may occur is because the foot (inset) does not receive the same tissue deformation and sensory stimulation as it does in the barefoot condition. Over time this may lead to a reduced demand on posterior chain muscles and a collapsing of the hip inwards in the frontal plane (above). Running using these mechanics is perhaps also more injurious because intrinsic foot muscles may be weaker from habitual footwear use (encouraging pronation; above) and lower limb muscles (especially posterior chain) may be less conditioned from modern sedentary lifestyles.

(extended knee) during shod running means that the heel is located further away from the centre of mass. Combined, these mechanics (upright posture and more extended lower limbs on ground contact) may increase repetitive tensile loading due to tissue elongation and prolonged eccentric muscle contraction (figure 2). ${ }^{79}$ 80 Addressing the neuromuscular deficits (reduced proximal and posterior chain muscle activity) associated with these mechanics has been shown to reduce the incidence of ACL injury in women's football. ${ }^{81}$ In the context of running, the earlier mentioned study by Tam and colleagues ${ }^{56}$ suggests that those considered responders to barefoot running demonstrate an increase in posterior chain muscle preactivation and reduced loading rates associated with an increase in plantar flexion angle (towards a forefoot strike). These changes, occurring in some runners, lead us to suggest that footwear may have a negative impact on loading mechanics via reducing the contribution of eccentric muscle work required from the posterior chain. It is perhaps unsurprising that proximal muscles of the posterior chain, such as the gluteal muscles, are the focus of many injury prevention and rehabilitation strategies across such a broad range of sports given their relevance in our evolutionary history.

\section{RUNNING FROM INJURY: THE ROLE OF BAREFOOT TRAINING IN SPORTS MEDICINE}

Proprioceptive training is recommended as an effective adjunct for the prevention and rehabilitation of musculoskeletal pathology in a range of sports. ${ }^{82-85}$ Equipment such as wobble boards, designed to create more unstable or less predictable conditions underfoot are used to challenge lower limb stability in particular around the foot and ankle. ${ }^{86}$ Exercises to improve intrinsic foot muscle strength have been prescribed and advanced by the stimulation of foot muscles in more functional positions. ${ }^{87}$ These approaches clearly have merit but we suggest that a highly task-specific form of proprioceptive training for runners would be to increase sensory input via the removal of shoes and to challenge it further by running (or walking initially) on less predictable surfaces such as firm grass or sand. In comparison to a control group $(n=7)$, runners $(n=10)$ encouraged to increase exposure to barefoot activity at home and when running for a period of 4 months, demonstrate a restoration in arch integrity as measured by a shortening of the medial arch and load redistribution towards the digits. Although, not controlled for, the authors suggest that the greatest adaptations were seen in those exposed to surfaces with greater variability. ${ }^{67}$ More recent data from a study of 57 runners reported increases in foot strength and muscle size from walking in minimalist footwear for 8 weeks. The changes observed were equivalent to that seen with a strengthening programme undertaken for the same duration $^{68}$ and are sufficient to alter propulsive forces during running. ${ }^{50}$ Therefore, it may be advisable for runners to engage in a foot strengthening programme in tandem with an increase in barefoot activities.

The kinematic changes (increased knee and plantar flexion) evident in some runners who transition to barefoot running seem to be similar to that experienced when running on an irregular surface. On an irregular surface, the knee and ankle appear to move in synchrony whereby the ankle stiffens and has a reduced rearfoot action. A spring-like ankle combined with an increase in knee flexion may increase impact attenuation. ${ }^{88}$ The task (barefoot running) and environmental (irregular surface) constraints may enhance the coordinated action of the spring-like function of the foot and the energy absorbing capacity of more proximal muscles. This form of training whereby the ground deforms underfoot also satisfies the need for variability to avoid overuse injury from repetitive microtrauma. Subtle differences in ground deformation and subsequent foot placement will challenge the biotensegrity of foot structures and the plantar cutaneous nerve receptors to respond with variations of tensioning and stiffening. These variations facilitate a consistent outcome (running) using different patterns of joint relations, a concept known as dynamical 
systems which has been described extensively in the literature. ${ }^{32}{ }^{89}{ }^{90}$ Lieberman and colleagues ${ }^{28}$ reported $72 \%$ of barefoot runners use a varied foot strike pattern compared with just $32 \%$ of shod runners. All runners used a more varied foot strike pattern on a softer surface. This form of training may be particularly important in older runners or those with a history of injury who are known to adopt more rigid behaviours. ${ }^{19}{ }^{91-93}$ In this case, the varied task and environmental constraints may assist in promoting variability in running action, subconsciously.

The challenge with this form of training is in the implementation. Gait retraining may be viewed as a more sensible alternative to barefoot training particularly in an urban environment and can address some of the kinematic changes needed to increase posterior chain muscle work. ${ }^{9495}$ A gait retraining strategy, using less cushioned footwear, may be useful in conjunction with barefoot running in order to allow transfer of a barefoot running style to urban environments. We have most experience implementing barefoot running practices in the UK and Ireland which benefit from northern Europe's marine west coast climate and ensures a pliable grass surface for the majority of the year. ${ }^{175396}$ Whether grass or sand is used, we suggest that a surface that is not too hard, that is, concrete and not too soft, that is, sand dunes, is important. A pliable surface allows the runner to maintain cadence while running with a freedom not afforded by running barefoot on concrete (at least initially). Conversely, a surface that is too soft makes the activity less like running and more like resistance exercise for the musculotendinous unit. We have used playing field surfaces to train 15 novice runners (9 female, 6 male) to run for up to $90 \mathrm{~min}$ barefoot in preparation for a half marathon, beginning with as little as 15 min. $^{96}$ The literature supports our view that barefoot running is well tolerated by most individuals when progressed in a careful manner, as is the case with any new exercise intervention. ${ }^{97-99}$ Although we recommend a cautious approach to integrating barefoot running and walking in previously shod adults, it should be noted that adolescents in New Zealand, classed as being habitually barefoot, are comfortable running distances of up to $3000 \mathrm{~m}$ barefoot on a tartan track.

The second challenge towards the implementation of barefoot running is part functional and part societal. Runners will no doubt be concerned about the exposure of the skin towards a roughened surface and the societal expectation to wear shoes in public. The skin of the plantar surface requires approximately $600 \%$ greater abrading loads to become painful by comparison to thigh region. ${ }^{44}$ It has been shown to adapt to wear and to deform with pressure from objects to avoid perforation. ${ }^{45}$ Furthermore, the foot calluses that develop to protect the sole of the foot do so without any trade-off in tactile sensitivity. ${ }^{57}$ The greater requirement for runners to look where they are going on such surfaces enhances the visual element of proprioceptive feedback and is usually sufficient to avoid perforation on surfaces such as playing fields which are well maintained. On surfaces regularly interrupted by sharp objects, a covering of the foot may be advised in the form of a minimalist shoe. Although, this dampens the direct sensory input to the cutaneous receptors, the absence of heel or arch support appears to encourage kinematics similar to the barefoot condition in comparison to cushioned minimalist or standard running shoes. ${ }^{58}$ During walking, impulse loading is still three times less in minimalist shoes relative to cushioned shoes. ${ }^{57}$ Although, these data appear to suggest barefoot/minimalist activity has a positive effect on biomechanical variables associated with injury, there is an insufficient number of studies which have directly assessed the impact of increasing barefoot activities on injury risk.

\section{CONCLUSION}

The structure and function of the human body represents our evolutionary legacy. In other words, the body we have today was created over the course of $\sim 6$ million years since our ancestors stood upright. In this context, we have been barefoot for almost the entirety of our existence. It is clear that some runners have adapted to our relatively new urban environment and footwear practices better than others. In essence, this review suggests that some (injury prone) runners may need more assistance from their innate impact moderating systems (evolutionary legacy) than others. We presented these innate moderating systems sequentially before discussing the impact that footwear may have on them. Although there are no conclusive data to suggest a causal link between footwear use and injury risk, we believe there are a number of compelling arguments for the inclusion of barefoot or minimalist training in a runner's programme, towards the aim of injury prevention. First, an increase in sensory input to the sole of the foot improves postural stability and therefore, fine control of movement. Second, intrinsic foot muscle size and strength improve with barefoot or minimalist activities leading to a restoration of the foot arch. ${ }^{100}$ Improving the integrity of the foot arch is one plausible strategy that could be used in an attempt to reduce the incidence of injuries associated with excessive deformation (pronation) of the arch. Third, individuals with extended lower limbs on ground contact demonstrate an increased reliance on passive tissues for shock absorption. The movement strategies used by such individuals, which underuse posterior muscles of the lower limb, are associated with both traumatic and overuse injuries of the knee. Many habitually barefoot runners do not use these mechanics and many runners who transition to barefoot running cease to use these mechanics. To reduce the load experienced by passive tissues during dynamic movement, greater hip, knee and ankle flexion are required. This requires greater eccentric muscle work by the posterior chain muscles. Whether this is achieved via neuromuscular training programmes, gait retraining or barefoot running, the evidence suggests that it has a positive impact on mechanics associated with injury and therefore, barefoot training also has potential in 
this regard. The transition towards barefoot activities in daily life, especially barefoot running, needs to be managed carefully in adults who have spent most of their lives shod. Slowly increasing time spent barefoot and on variable surfaces may provide a suitable introduction to barefoot training for previously shod individuals. In this way, adults may be able to restore innate impact moderating mechanisms, associated with their evolutionary legacy, without muscle-tendon strain.

\section{FUTURE RESEARCH DIRECTIONS}

Many of the suggestions in this paper although based on a plausible logic and reason, are speculative and not evidence based. We propose the following research directions to advance understanding in this area:

- Prospective injury audits of barefoot and shod runners would add to the existing data published by Altman and Davis. ${ }^{74}$ Understanding the prevalence and incidence of injury experienced by both populations is important to inform injury prevention and rehabilitation strategies and because it gives scientists some initial clues about the loading characteristics of both runners.

- Studies that seek to understand neuromuscular adaptation of previously shod runners to barefoot running on a variety of surfaces are required. Tam and colleagues ${ }^{56}$ have performed some of the most informative work in this regard because they sought to group responders and non-responders in terms of kinematics, muscle work and loading rates. These studies are difficult to conduct due to the resources required but are badly needed to advance understanding in this field.

- A greater understanding of the characteristics of runners who do not get injured or are injured infrequently are required. This may shed light on beneficial running mechanics, training patterns or muscle-tendon unit function. This may serve to provide greater clarity on why barefoot training may be useful for some runners but not others.

- Available data suggest shod and barefoot runners both experience Achilles tendinopathy. Studies which can shed light on how a rearfoot or mid to forefoot strike contributes to Achilles tendon overload, are required.

- Follow-up data that can determine whether childrenadolescents growing up habitually barefoot or shod have a different prevalence and incidence of running injury as adults.

- Studies into different methods for introducing barefoot or minimalist activities in urban environments, especially to determine the appropriate dose response that will maximise adaptation and minimise injury risk.

- We have begun to conduct research on the role of barefoot/minimalist activities in the treatment of patients with existing musculoskeletal conditions, namely plantar fasciitis. ${ }^{17101}$ The role of such activities for the treatment and rehabilitation of existing injuries requires further attention.

Acknowledgements The authors thank artist Dominika Stoppa for the illustrations in figures 1 and 2 .

Contributors PF performed the literature search and wrote the initial manuscript. GS reviewed, edited and wrote sections of the final manuscript.

Funding The authors have not declared a specific grant for this research from any funding agency in the public, commercial or not-for-profit sectors.

Competing interests None declared.

Patient consent for publication Not required.

Provenance and peer review Not commissioned; externally peer reviewed.

Data availability statement There are no data in this work.

Open access This is an open access article distributed in accordance with the Creative Commons Attribution Non Commercial (CC BY-NC 4.0) license, which permits others to distribute, remix, adapt, build upon this work non-commercially, and license their derivative works on different terms, provided the original work is properly cited, appropriate credit is given, any changes made indicated, and the use is non-commercial. See: http://creativecommons.org/licenses/by-nc/4.0/.

\section{ORCID iD}

Peter Francis http://orcid.org/0000-0002-9720-6253

\section{REFERENCES}

1 Lieberman DE. What we can learn about running from barefoot running: an evolutionary medical perspective. Exerc Sport Sci Rev 2012;40:63-72.

2 Trinkaus E. Anatomical evidence for the antiquity of human footwear use. J Archaeol Sci 2005;32:1515-26.

3 Kuttruff JT, DeHart SG, O'Brien MJ. 7500 years of prehistoric footwear from Arnold research cave, Missouri. Science 1998;281:72-5.

4 Hoffmann P. Conclusions drawn from a comparative study of the feet of barefooted and shoe-wearing peoples. Am J Orthop Surg 1905;2:105-36.

5 Davis IS. The re-emergence of the minimal running shoe. J Orthop Sports Phys Ther 2014;44:775-84.

6 Lieberman D. The story of the human body: evolution, health, and disease, 2014.

7 Hu FB. Globalization of diabetes: the role of diet, lifestyle, and genes. Diabetes Care 2011;34:1249-57.

8 Court-Brown CM, Clement ND, Duckworth AD, et al. The changing epidemiology of fall-related fractures in adults. Injury 2017;48:819-24.

9 Rajput B, Abboud RJ. Common ignorance, major problem: the role of footwear in plantar fasciitis. Foot 2004;14:214-8.

10 Hollander K, Liebl D, Meining S, et al. Adaptation of running biomechanics to repeated barefoot running: a randomized controlled study. Am J Sports Med 2019;47:1975-83.

11 Francis P, Tucker BC, Oddy C, et al. Adaptation of running biomechanics to repeated barefoot running: a randomized controlled study: letter to the editor. Am J Sports Med 2019;48.

12 McKeon PO, Hertel J, Bramble D, et al. The foot core system: a new paradigm for understanding intrinsic foot muscle function. $\mathrm{Br} J$ Sports Med 2015;49:290.

13 Alexander RM. Energy-saving mechanisms in walking and running. $J$ Exp Biol 1991;160:55-69.

14 Venkadesan M, Yawar A, Eng CM, et al. Stiffness of the human foot and evolution of the transverse arch. Nature 2020;579:97-100.

15 Perl DP, Daoud AI, Lieberman DE. Effects of footwear and strike type on running economy. Med Sci Sports Exerc 2012;44:1335-43.

16 Hasegawa $\mathrm{H}$, Yamauchi T, Kraemer WJ. Foot strike patterns of runners at the $15-\mathrm{km}$ point during an elite-level half marathon. $J$ Strength Cond Res 2007;21:888-93.

17 Francis P, Oddy C, Johnson MI. Reduction in plantar heel pain and a return to sport after a barefoot running intervention in a female Triathlete with plantar fasciitis. Int J Athl Ther Trai 2017;22:26-32.

18 Daoud Al, Geissler GJ, Wang F, et al. Foot strike and injury rates in endurance runners: a retrospective study. Med Sci Sports Exerc 2012;44:1325-34.

19 Pohl MB, Hamill J, Davis IS. Biomechanical and anatomic factors associated with a history of plantar fasciitis in female runners. Clin J Sport Med 2009;19:372-6. 
20 Lieberman DE, Venkadesan M, Werbel WA, et al. Foot strike patterns and collision forces in habitually barefoot versus shod runners. Nature 2010;463:531-5.

21 Malisoux L, Nielsen RO, Urhausen A, et al. A step towards understanding the mechanisms of running-related injuries. J Sci Med Sport 2015;18:523-8.

22 Fitzharris $\mathrm{N}$, Jones $\mathrm{G}$, Jones $\mathrm{A}$, et al. The first prospective injury audit of League of Ireland footballers. BMJ Open Sport Exerc Med 2017:3:e000220.

23 Francis $\mathrm{P}$, Whatman $\mathrm{C}$, Sheerin $\mathrm{K}$, et al. The proportion of lower limb running injuries by gender, anatomical location and specific pathology: a systematic review. J Sports Sci Med 2019;18:21-31.

24 Hanley B, Bissas A, Merlino S, et al. Most marathon runners at the 2017 IAAF world Championships were rearfoot strikers, and most did not change footstrike pattern. J Biomech 2019;92:54-60.

25 Hatala KG, Dingwall HL, Wunderlich RE, et al. Variation in foot strike patterns during running among habitually barefoot populations. PLoS One 2013;8:e52548.

26 Hollander K, de Villiers JE, Venter R, et al. Foot strike patterns differ between children and adolescents growing up barefoot vs. Shod. Int J Sports Med 2018:39:97-103.

27 Pontzer H, Suchman K, Raichlen DA, et al. Foot strike patterns and hind limb joint angles during running in Hadza hunter-gatherers. $J$ Sport Health Sci 2014;3:95-101.

28 Lieberman DE, Castillo ER, Otarola-Castillo E, et al. Variation in foot strike patterns among habitually barefoot and Shod runners in Kenya. PLoS One 2015;10:e0131354.

29 Willwacher S, Fischer KM, Rohr E, et al. Surface stiffness and footwear affect the loading stimulus for lower extremity muscles when running. J Strength Cond Res 2020:1.

30 Warne JP, Warrington GD. Four-week habituation to simulated barefoot running improves running economy when compared with shod running. Scand J Med Sci Sports 2014;24:563-8.

31 Lindlein $\mathrm{K}$, Zech $\mathrm{A}$, Zoch $\mathrm{A}$, et al. Improving running economy by transitioning to minimalist footwear: a randomised controlled trial. $J$ Sci Med Sport 2018;21:1298-303.

32 Kiely J, Collins DJ. Uniqueness of human running coordination: the integration of modern and ancient evolutionary innovations. Front Psychol 2016;7:262.

33 Moritz CT, Farley CT. Passive dynamics change leg mechanics for an unexpected surface during human hopping. J Appl Physiol 2004:97:1313-22.

34 Smith SGVS, Yokich MK, Beaudette SM, et al. Effects of foot position on skin structural deformation. J Mech Behav Biomed Mater 2019;95:240-8.

35 Perry SD, Santos LC, Patla AE. Contribution of vision and cutaneous sensation to the control of centre of mass (com) during gait termination. Brain Res 2001;913:27-34.

36 Jenkins ME, Almeida QJ, Spaulding SJ, et al. Plantar cutaneous sensory stimulation improves single-limb support time, and EMG activation patterns among individuals with Parkinson's disease. Parkinsonism Relat Disord 2009;15:697-702.

37 Hicks JH. The mechanics of the foot. II. The plantar aponeurosis and the arch. J Anat 1954;88:25-30

38 Ker RF, Bennett MB, Bibby SR, et al. The spring in the arch of the human foot. Nature 1987;325:147-9.

39 Daley MA, Felix G, Biewener AA. Running stability is enhanced by a proximo-distal gradient in joint neuromechanical control. J Exp Biol 2007:210:383-94.

40 van der Krogt MM, de Graaf WW, Farley CT, et al. Robust passive dynamics of the musculoskeletal system compensate for unexpected surface changes during human hopping. J Appl Physiol 2009;107:801-8.

41 Thorstensson A, Grimby G, Karlsson J. Force-Velocity relations and fiber composition in human knee extensor muscles. J Appl Physiol 1976;40:12-16.

42 Strzalkowski NDJ, Incognito AV, Bent LR, et al. Cutaneous mechanoreceptor feedback from the hand and foot can modulate muscle sympathetic nerve activity. Front Neurosci 2016;10:568.

43 Strzalkowski NDJ, Peters RM, Inglis JT, et al. Cutaneous afferent innervation of the human foot sole: what can we learn from singleunit recordings? J Neurophysiol 2018;120:1233-46.

44 Robbins S, Gouw GJ, McClaran J, et al. Protective sensation of the plantar aspect of the foot. Foot Ankle 1993;14:347-52.

45 Robbins SE, Gouw GJ, Hanna AM. Running-related injury prevention through innate impact-moderating behavior. Med Sci Sports Exerc 1989;21:130-139.

46 Nurse MA, Nigg BM. The effect of changes in foot sensation on plantar pressure and muscle activity. Clin Biomech 2001:16:719-27.
47 Höhne A, Ali S, Stark C, et al. Reduced plantar cutaneous sensation modifies gait dynamics, lower-limb kinematics and muscle activity during walking. Eur J Appl Physiol 2012;112:3829-38.

48 Howe EE, Toth AJ, Vallis LA, et al. Baseline skin information from the foot dorsum is used to control lower limb kinematics during level walking. Exp Brain Res 2015;233:2477-87.

49 Agrawal Y, Carey JP, Della Santina CC, et al. Disorders of balance and vestibular function in US adults: data from the National health and nutrition examination survey, 2001-2004. Arch Intern Med 2009;169:938-44.

50 Taddei UT, Matias AB, Ribeiro FIA, et al. Effects of a foot strengthening program on foot muscle morphology and running mechanics: a proof-of-concept, single-blind randomized controlled trial. Phys Ther Sport 2020;42:107-15.

51 Falla D, Jull G, Hodges PW. Feedforward activity of the cervical flexor muscles during voluntary arm movements is delayed in chronic neck pain. Exp Brain Res 2004;157:43-8.

52 Steilen D, Hauser R, Woldin B, et al. Chronic neck pain: making the connection between capsular ligament laxity and cervical instability. Open Orthop J 2014;8:326-45.

53 Francis $\mathrm{P}$, Ledingham J, Clarke S, et al. A comparison of Stride length and lower extremity kinematics during barefoot and Shod running in well trained distance runners. J Sports Sci Med 2016;15:417-23.

54 Divert C, Mornieux G, Baur H, et al. Mechanical comparison of barefoot and shod running. Int J Sports Med 2005;26:593-8.

55 Ahn AN, Brayton C, Bhatia T, et al. Muscle activity and kinematics of forefoot and rearfoot strike runners. J Sport Health Sci 2014;3:102-12.

56 Tam N, Tucker R, Astephen Wilson JL. Individual responses to a barefoot running program: insight into risk of injury. Am J Sports Med 2016;44:777-84.

57 Holowka NB, Wynands B, Drechsel TJ, et al. Foot callus thickness does not trade off protection for tactile sensitivity during walking. Nature 2019;571:261-4.

58 Hollander K, Argubi-Wollesen A, Reer R, et al. Comparison of minimalist footwear strategies for simulating barefoot running: a randomized crossover study. PLoS One 2015;10:e0125880.

59 D'AoÛt K, Pataky TC, De Clercq D, et al. The effects of habitual footwear use: foot shape and function in native barefoot walkers†. Footwear Sci 2009;1:81-94.

60 Franklin S, Grey MJ, Heneghan N, et al. Barefoot vs common footwear: a systematic review of the kinematic, kinetic and muscle activity differences during walking. Gait Posture 2015;42:230-9.

61 Stolwijk NM, Duysens J, Louwerens JWK, et al. Flat feet, happy feet? comparison of the dynamic plantar pressure distribution and static medial foot geometry between Malawian and Dutch adults. PLoS One 2013;8:e57209.

62 Rao UB, Joseph $B$. The influence of footwear on the prevalence of flat foot. A survey of 2300 children. J Bone Joint Surg Br 1992;74:525-7.

63 Echarri JJ, Forriol F. The development in footprint morphology in 1851 Congolese children from urban and rural areas, and the relationship between this and wearing shoes. $J$ Pediatr Orthop $B$ 2003;12:141-6.

64 Hollander K, Heidt C, VAN DER Zwaard BC, et al. Long-Term effects of habitual barefoot running and walking: a systematic review. Med Sci Sports Exerc 2017:49:752-62.

65 Headlee DL, Leonard JL, Hart JM, et al. Fatigue of the plantar intrinsic foot muscles increases navicular drop. J Electromyogr Kinesiol 2008;18:420-5.

66 Fiolkowski P, Brunt D, Bishop M, et al. Intrinsic pedal musculature support of the medial longitudinal arch: an electromyography study. $J$ Foot Ankle Surg 2003:42:327-33.

67 Robbins SE, Hanna AM. Running-related injury prevention through barefoot adaptations. Med Sci Sports Exerc 1987;19:148-56.

68 Ridge ST, Olsen MT, Bruening DA, et al. Walking in minimalist shoes is effective for strengthening foot muscles. Med Sci Sports Exerc 2019;51:104-13.

69 Busseuil C, Freychat P, Guedj EB, et al. Rearfoot-forefoot orientation and traumatic risk for runners. Foot Ankle Int 1998;19:32-7.

70 Bennett JE, Reinking MF, Pluemer B, et al. Factors contributing to the development of medial tibial stress syndrome in high school runners. J Orthop Sports Phys Ther 2001;31:504-10.

71 Willems TM, Witvrouw E, De Cock A, et al. Gait-related risk factors for exercise-related lower-leg pain during shod running. Med Sci Sports Exerc 2007;39:330-9.

72 Williams DS. 3Rd, McClay is, Hamill J. arch structure and injury patterns in runners. Clinical biomechanics 2001;16:341-7. 
73 Goss DL, Gross MT. Relationships among self-reported shoe type, footstrike pattern, and injury incidence. US Army Med Dep J 2012:25-30.

74 Altman AR, Davis IS. Prospective comparison of running injuries between shod and barefoot runners. Br J Sports Med 2016;50:476-80.

75 Powers CM. The influence of abnormal hip mechanics on knee injury: a biomechanical perspective. J Orthop Sports Phys Ther 2010;40:42-51.

76 Myer GD, Ford KR, Di Stasi SL, et al. High knee abduction moments are common risk factors for patellofemoral pain (PFP) and anterior cruciate ligament (ACL) injury in girls: is PFP itself a predictor for subsequent ACL injury? Br J Sports Med 2015;49:118-22.

77 Di Stasi S, Myer GD, Hewett TE. Neuromuscular training to target deficits associated with second anterior cruciate ligament injury. $J$ Orthop Sports Phys Ther 2013;43:777-A11.

78 Hewett TE, Ford KR, Hoogenboom BJ, et al. Understanding and preventing acl injuries: current biomechanical and epidemiologic considerations - update 2010. N Am J Sports Phys Ther 2010;5:234-51.

79 Ruder M, Jamison ST, Tenforde A, et al. Relationship of foot strike pattern and landing impacts during a marathon. Med Sci Sports Exerc 2019;51:2073-9.

80 Lohman EB, Balan Sackiriyas KS, Swen RW. A comparison of the spatiotemporal parameters, kinematics, and biomechanics between shod, unshod, and minimally supported running as compared to walking. Phys Ther Sport 2011;12:151-63.

81 Sugimoto D, Myer GD, Foss KDB, Barber Foss KD, et al. Specific exercise effects of preventive neuromuscular training intervention on anterior cruciate ligament injury risk reduction in young females: meta-analysis and subgroup analysis. Br J Sports Med 2015;49:282-9

82 Riva D, Bianchi R, Rocca F, et al. Proprioceptive training and injury prevention in a professional men's Basketball team: a six-year prospective study. J Strength Cond Res 2016;30:461-75.

83 Paszkewicz J, Webb T, Waters B, et al. The effectiveness of injury-prevention programs in reducing the incidence of anterior cruciate ligament sprains in adolescent athletes. J Sport Rehabil 2012;21:371-7.

84 Steffen K, Emery CA, Romiti M, et al. High adherence to a neuromuscular injury prevention programme (FIFA 11+) improves functional balance and reduces injury risk in Canadian youth female football players: a cluster randomised trial. Br J Sports Med 2013;47:794-802.

85 Zech A, Hübscher M, Vogt L, et al. Neuromuscular training for rehabilitation of sports injuries: a systematic review. Med Sci Sports Exerc 2009;41:1831-41.
86 Linens SW, Ross SE, Arnold BL. Wobble board rehabilitation for improving balance in Ankles with chronic instability. Clin J Sport Med 2016;26:76-82.

87 McKeon PO, Fourchet F. Freeing the foot: integrating the foot core system into rehabilitation for lower extremity injuries. Clin Sports Med 2015;34:347-61.

88 Thomas JM, Derrick TR. Effects of step uncertainty on impact peaks, shock attenuation, and knee/subtalar synchrony in treadmill running. J Appl Biomech 2003;19:60-70.

89 Davids K, Glazier P. Deconstructing neurobiological coordination: the role of the biomechanics-motor control nexus. Exerc Sport Sci Rev 2010;38:86-90.

90 Davids K, Glazier P, Araújo D, et al. Movement systems as dynamical systems: the functional role of variability and its implications for sports medicine. Sports Med 2003;33:245-60.

91 Davids K, Kingsbury D, George K, et al. Interacting constraints and the emergence of postural behavior in ACL-Deficient subjects. $J$ Mot Behav 1999;31:358-66.

92 Horak FB, Nutt JG, Nashner LM. Postural inflexibility in parkinsonian subjects. J Neurol Sci 1992;111:46-58.

93 Schieppati M, Hugon M, Grasso M, et al. The limits of equilibrium in young and elderly normal subjects and in parkinsonians. Electroencephalogr Clin Neurophysiol 1994;93:286-98.

94 Noehren B, Scholz J, Davis I. The effect of real-time gait retraining on hip kinematics, pain and function in subjects with patellofemoral pain syndrome. Br J Sports Med 2011;45:691-6.

95 Crowell HP, Davis IS. Gait retraining to reduce lower extremity loading in runners. Clin Biomech 2011;26:78-83.

96 FrancisP. To run SHOD or not SHOD: are we asking the right question? Co-Kinetic Journal 2017;74.

97 Mullen S, Cotton J, Bechtold M, et al. Barefoot running: the effects of an 8-Week barefoot training program. Orthop J Sports Med 2014;2:2325967114525582.

98 McCarthy C, Fleming N, Donne B, et al. 12 weeks of simulated barefoot running changes foot-strike patterns in female runners. Int J Sports Med 2014;35:443-50.

99 Tam N, Tucker R, Astephen Wilson JL, et al. Effect on oxygen cost of transport from 8-Weeks of progressive training with barefoot running. Int J Sports Med 2015;36:1100-5.

100 Holowka NB, Wallace IJ, Lieberman DE. Foot strength and stiffness are related to footwear use in a comparison of minimally- vs. conventionally-shod populations. Sci Rep 2018;8:3679.

101 Oddy C, Walker A, Francis P. Barefoot running as a treatment for plantar fasciitis in the runner: a case series. Med Sci Sports Exerc 2019;51:848-9. 